Manuscript No: JP063957I

\title{
Direct Synthesis of Well-Ordered and Unusually Reactive MnSBA-15 Mesoporous Molecular Sieves with high manganese content
}

M. Selvaraj, and T.G. Lee

Supporting information 


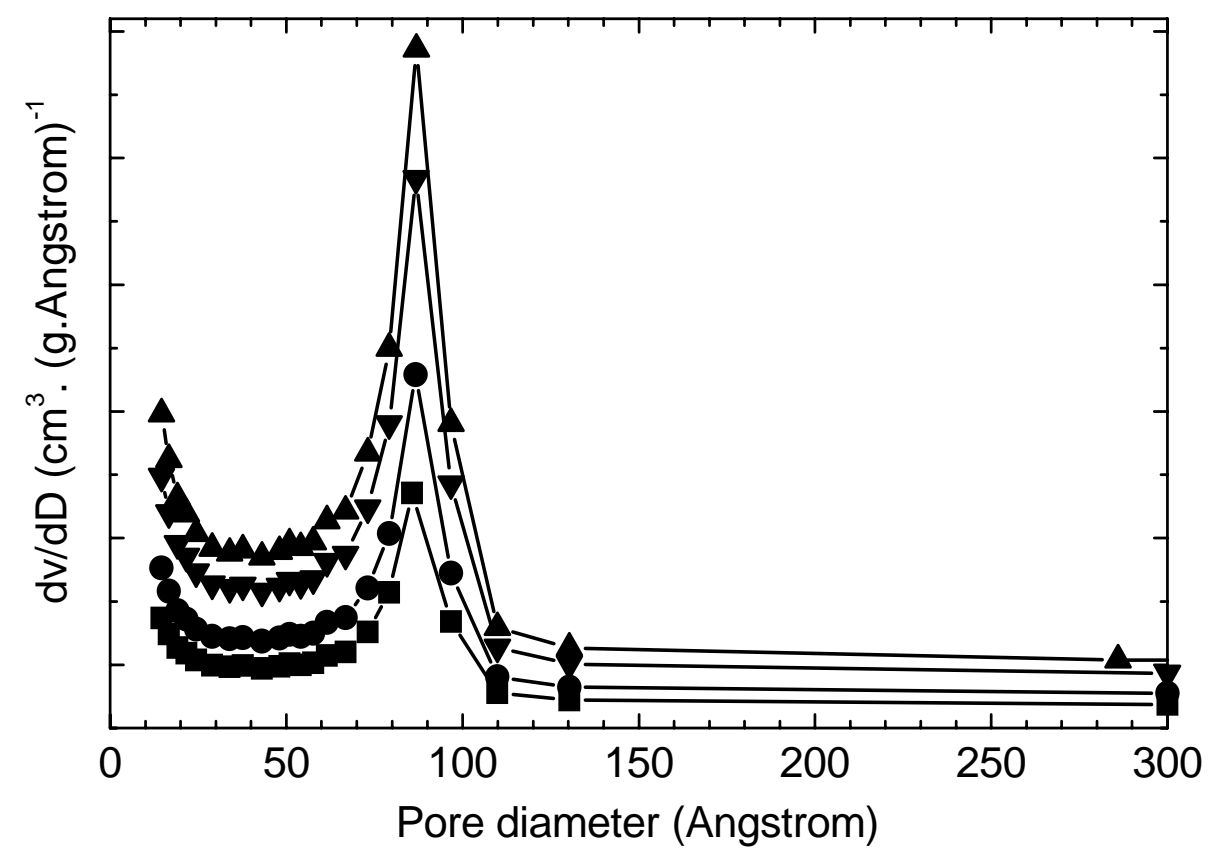

Figure 1S. BJH pore size distributions for calcined MnSBA-15 materials prepared with

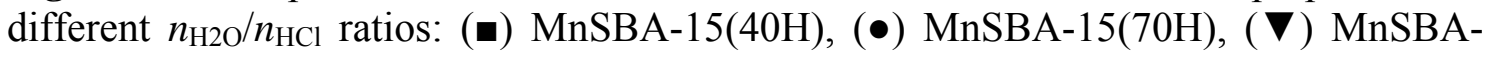
15(166H), and ( $\mathbf{\Delta})$ MnSBA-15(295H). 

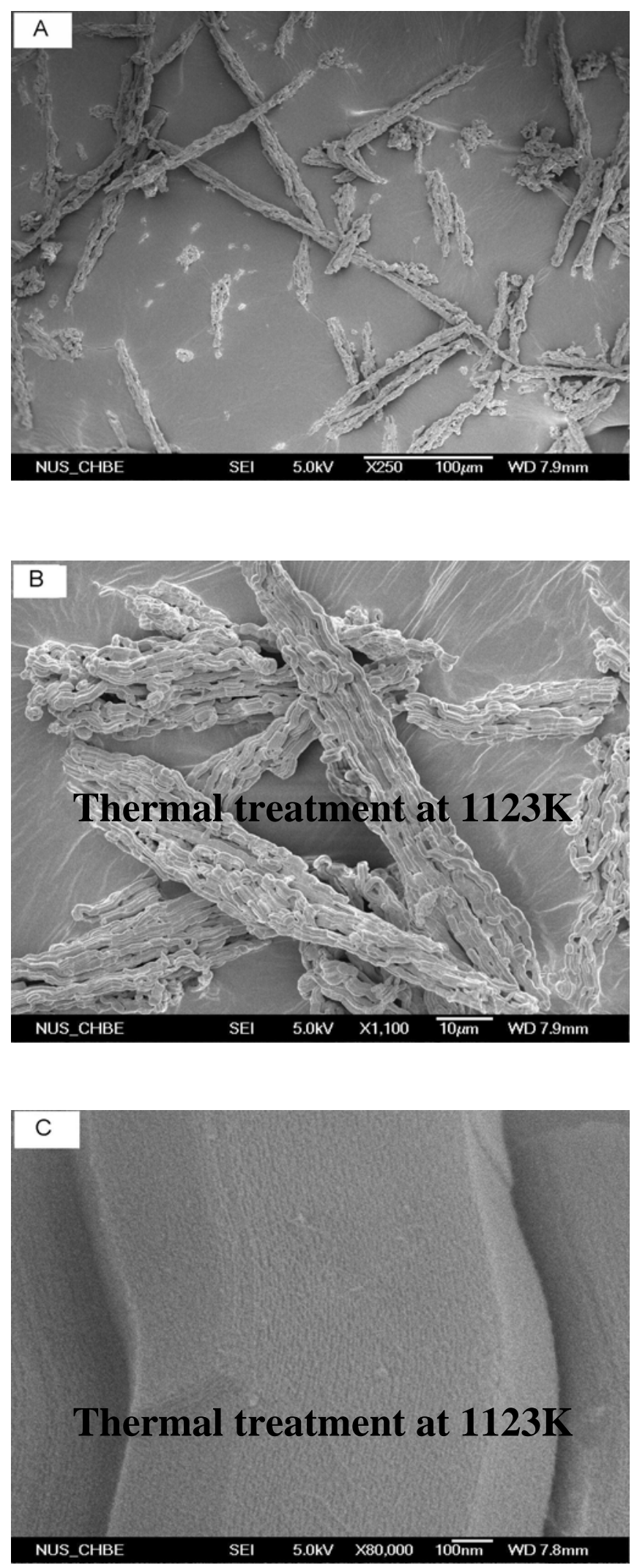

Figure 2S. FE-SEM images for MnSBA-15(295H) 
Table 1S. Physico-chemical characterization of MnSBA-15 after hydrothermal treatment.

\begin{tabular}{ccccccccc}
\hline \multirow{2}{*}{ sample } & \multicolumn{2}{c}{$n_{\mathrm{Si}} / n_{\mathrm{Mn}}$ ratio } & & & & & \\
\cline { 2 - 6 } & Gel & Product $^{\mathrm{a}}$ & $\begin{array}{c}d_{100} \\
(\AA)\end{array}$ & $\begin{array}{c}a_{\mathrm{o}} \\
(\AA)\end{array}$ & $\begin{array}{c}A_{\mathrm{BET}} \\
\left(\mathrm{m}^{2} / \mathrm{g}\right)\end{array}$ & $\begin{array}{c}d_{\mathrm{p}} \\
(\AA)\end{array}$ & $\begin{array}{c}V_{\mathrm{p}} \\
\left(\mathrm{cm}^{3} / \mathrm{g}\right)\end{array}$ & $\begin{array}{c}t_{\mathrm{w}}=a_{\mathrm{o}}-d_{\mathrm{p}} \\
(\AA)\end{array}$ \\
\hline MnSBA-15(2) & 4 & 2.2 & 107.6 & 124.2 & 996 & 86.9 & 1.12 & 37.3 \\
MnSBA-15(26) & 50 & 26.4 & 99.9 & 115.3 & 999 & 83.3 & 1.07 & 32.0 \\
\hline
\end{tabular}

${ }^{\text {a }}$ The results of $n_{\mathrm{Si}} / n_{\mathrm{Mn}}$ ratios in the products are determined by ICP-AES; $a_{0}$, unit cell parameter; $A_{\mathrm{BET}}$, specific surface area; $d_{\mathrm{p}}$, pore diameter; $V_{\mathrm{p}}$, pore volume; pore wall thickness $\left(t_{\mathrm{w}}\right)=$ unit cell parameter $\left(a_{0}\right)-$ pore diameter $\left(d_{\mathrm{p}}\right)$.

Table 2S. Physico-chemical characterization of MnSBA-15 after thermal treatment.

\begin{tabular}{|c|c|c|c|c|c|c|c|c|c|}
\hline \multirow[b]{2}{*}{ sample } & \multirow[b]{2}{*}{$\begin{array}{c}\text { Thermal } \\
\text { treatment }\end{array}$} & \multicolumn{2}{|c|}{$n_{\mathrm{Si}} / n_{\mathrm{Mn}}$ ratio } & \multirow[b]{2}{*}{$\begin{array}{l}d_{100} \\
(\AA)\end{array}$} & \multirow[b]{2}{*}{$\begin{array}{c}a_{\mathrm{o}} \\
(\AA \AA)\end{array}$} & \multirow[b]{2}{*}{$\begin{array}{c}A_{\mathrm{BET}} \\
\left(\mathrm{m}^{2} / \mathrm{g}\right)\end{array}$} & \multirow[b]{2}{*}{$\begin{array}{c}d_{\mathrm{p}} \\
(\AA)\end{array}$} & \multirow[b]{2}{*}{$\begin{array}{c}V_{\mathrm{p}} \\
\left(\mathrm{cm}^{3} / \mathrm{g}\right)\end{array}$} & \multirow[b]{2}{*}{$\begin{array}{c}t_{\mathrm{w}}=\underset{\mathrm{o}}{a_{\mathrm{o}}-d_{\mathrm{p}}} \\
(\AA)\end{array}$} \\
\hline & & Gel & Product $^{\mathrm{a}}$ & & & & & & \\
\hline \multirow[t]{2}{*}{ MnSBA-15(2) } & $973 \mathrm{~K}$ & 4 & 2.2 & 107.6 & 124.2 & 997 & 86.9 & 1.12 & 37.3 \\
\hline & $1123 \mathrm{~K}$ & 4 & 2.2 & 107.6 & 124.2 & 995 & 86.9 & 1.12 & 37.3 \\
\hline \multirow[t]{2}{*}{ MnSBA-15(26) } & $973 \mathrm{~K}$ & 50 & 26.4 & 99.8 & 115.2 & 998 & 83.2 & 1.07 & 32.0 \\
\hline & $1123 \mathrm{~K}$ & 50 & 26.4 & 99.7 & 115.1 & 900 & 83.1 & 1.07 & 32.0 \\
\hline
\end{tabular}

${ }^{\text {a }}$ The results of $n_{\mathrm{Si}} / n_{\mathrm{Mn}}$ ratios in the products are determined by ICP-AES; $a_{0}$, unit cell parameter; $A_{\mathrm{BET}}$, specific surface area; $d_{\mathrm{p}}$, pore diameter; $V_{\mathrm{p}}$, pore volume; pore wall thickness $\left(t_{\mathrm{w}}\right)=$ unit cell parameter $\left(a_{0}\right)$ - pore diameter $\left(d_{\mathrm{p}}\right)$. 
Table 3S. Epoxidation of trans-stilbene for different catalysts ${ }^{\text {a }}$

\begin{tabular}{ccccccc}
\hline \multirow{2}{*}{$\begin{array}{c}\text { Catalysts } \\
\text { (Si/metal (s) ratio) }\end{array}$} & \multicolumn{3}{c}{ Yield (\%) } & $\begin{array}{c}\text { Conv. } \\
(\%)\end{array}$ & TSO Selectivity & $\begin{array}{c}\text { Reference } \\
\text { Number }\end{array}$ \\
\cline { 2 - 5 } & TSO & B & BA & & & \\
\hline & & & & & 99.1 & - \\
MnSBA-15(2) & 97.6 & 0.6 & 0.2 & 98.4 & 84.58 & 15 \\
ZrMnMCM-41(49) & 76.3 & 11.1 & 2.8 & 90.2 & 81.67 & 15 \\
MnMCM-41(31) & 57.5 & 10.7 & 2.2 & 70.4 & 96.15 & 2 \\
MnMCM-41(64) & 50.0 & - & - & 52 & & \\
\hline
\end{tabular}

${ }^{\mathrm{a}}$ Reaction conditions: $0.2 \mathrm{~g}$ of catalyst; $\mathrm{T}=338 \mathrm{~K} ; \mathrm{t}=24 \mathrm{~h}$; $\mathrm{TS}$ and $\mathrm{TBHP}$ mmol ratio $=$ 1:10; solvent ratio $=\operatorname{MeCN}(9 \mathrm{ml}): \mathrm{DMF}(1 \mathrm{ml}) ;{ }^{\mathrm{b}} \mathrm{T}=328 \mathrm{~K}$. 